\title{
Corrigenda
}

\section{Correction: A Newly Developed Web-Based Resource on Genetic Eye Disorders for Users With Visual Impairment (Gene.Vision): Usability Study}

Jian Lee Yeong ${ }^{1 *}$, MBChB; Peter Thomas ${ }^{2 *}$, MA, BM, BCS, FRCOphth, PhD; James Buller ${ }^{3}$, BSc; Mariya Moosajee ${ }^{1,2,4}$, BSc, MBBS, PhD, FRCOphth

\footnotetext{
${ }^{1}$ Institute of Ophthalmology, University College London, London, United Kingdom

${ }^{2}$ Moorfields Eye Hospital NHS Foundation Trust, London, United Kingdom

${ }^{3}$ Aniridia Network, Sheffield, United Kingdom

${ }^{4}$ Great Ormond Street Hospital for Children NHS Foundation Trust, London, United Kingdom

*these authors contributed equally
}

\section{Corresponding Author:}

Mariya Moosajee, BSc, MBBS, PhD, FRCOphth

Institute of Ophthalmology

University College London

11-43 Bath Street

London, EC1V 9EL

United Kingdom

Phone: 12076086800

Email: m.moosajee@ucl.ac.uk

\section{Related Article:}

Correction of: http://www.jmir.org/2021/1/e19151/

(J Med Internet Res 2021;23(1):e27330) doi: 10.2196/27330

In "A Newly Developed Web-Based Resource on Genetic Eye Disorders for Users With Visual Impairment (Gene.Vision): Usability Study" (J Med Internet Res 2021;23(1):e19151) the authors noted one error.

In the originally published article, additional text was inadvertently included at end of the Background section of the Abstract. It read as follows:

Despite the introduction of the Web Content Accessibility Guidelines and legislations, many websites remain poorly accessible to users with disability, especially those with visual impairment, as the internet has become a more visually complex environment. With increasing reliance on the internet and almost 2 million people in the United Kingdom being affected by vision loss, it is important that they are not overlooked when developing web-based materials. A significant proportion of those affected have irreversible vision loss due to rare genetic eye disorders, and many of them use the internet as a primary source of information for their conditions. However, access to high-quality web-based health information with an inclusive design remains a challenge for many. We have developed a new web-based resource for genetic eye disorders called Gene.Vision that aims to provide a holistic guide for patients, relatives, and health care professionals. by sight loss, it is important that they are not overlooked when developing web-based materials. A significant proportion of those affected have irreversible sight loss due to rare genetic eye disorders, and many of them use the internet as a primary source of information for their conditions. However, access to high-quality web-based health information with an inclusive design remains a challenge for many.

This section has been revised to:

Despite the introduction of the Web Content Accessibility Guidelines and legislations, many websites remain poorly accessible to users with disability, especially those with visual impairment, as the internet has become a more visually complex environment. With increasing reliance on the internet and almost 2 million people in the United Kingdom being affected by vision loss, it is important that they are not overlooked when developing web-based materials. A significant proportion of those affected have irreversible vision loss due to rare genetic eye disorders, and many of them use the internet as a primary source of information for their conditions. However, access to high-quality web-based health information with an inclusive design remains a challenge for many. We have developed a new web-based resource for genetic eye disorders called 
Gene.Vision that aims to provide a holistic guide for patients, relatives, and health care professionals.

The correction will appear in the online version of the paper on the JMIR Publications website on January 25, 2021, together with the publication of this correction notice. Because this was made after submission to PubMed, PubMed Central, and other full-text repositories, the corrected article has also been resubmitted to those repositories.

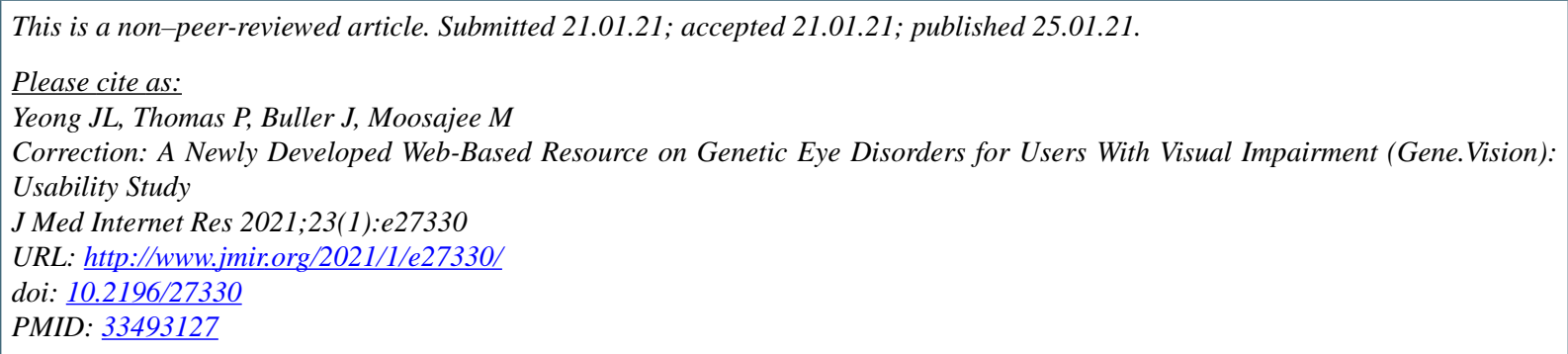

CJian Lee Yeong, Peter Thomas, James Buller, Mariya Moosajee. Originally published in the Journal of Medical Internet Research (http://www.jmir.org), 25.01.2021. This is an open-access article distributed under the terms of the Creative Commons Attribution License (https://creativecommons.org/licenses/by/4.0/), which permits unrestricted use, distribution, and reproduction in any medium, provided the original work, first published in the Journal of Medical Internet Research, is properly cited. The complete bibliographic information, a link to the original publication on http://www.jmir.org/, as well as this copyright and license information must be included. 